\title{
Impact of type of tooth on outcome of non-surgical root canal treatment
}

\author{
Erika Laukkanen ${ }^{1,2,3}$ (D) Miira M. Vehkalahti ${ }^{1} \cdot$ Anja K. Kotiranta ${ }^{1,2,3}$ \\ Received: 16 February 2018 / Accepted: 25 January 2019 / Published online: 2 February 2019 \\ (C) The Author(s) 2019
}

\begin{abstract}
Objectives We assessed the impact of type of tooth on the outcome of root canal treatment (RCT) according to factors potentially weakening the prognosis such as preoperative apical periodontitis (AP) and treatment modality (primary or secondary RCT).

Materials and methods We scrutinized patient documents including pre- and postoperative radiographs of 640 permanent teeth receiving non-surgical RCT at Helsinki University Clinic in 2008-2011. Of teeth, 44\% were molars, 32\% premolars, and 24\% anterior teeth. Patients' mean age was 51.5 years; $51 \%$ were male. AP was present in $60.5 \%$ of teeth preoperatively. We used the periapical index (PAI) to assess the radiographs and defined radiographically "healthy" and "healing" cases as successful. Statistical evaluation included chi-squared tests, Fisher's exact tests, $t$ tests, and logistic regression modeling.

Results The overall success rate (SR) was $84.1 \% ; 88.3 \%$ for primary and $75.5 \%$ for secondary RCT $(p<0.001)$. The SRs for anterior teeth, premolars and molars were $85.6 \%, 88.8 \%$, and 79.7\%, respectively. Teeth with and without AP had SRs of 77.3\% and $94.5 \%$, respectively $(p<0.001)$. The RCTs were more likely to succeed in anterior teeth and premolars than in molars (OR $1.7 ; 95 \%$ CI 1.1-2.7) and in females than in males (OR 1.9; 95\% CI 1.2-3.1).

Conclusions Apart from existing AP and retreatment scenario, also, the type of tooth and gender had a significant influence on the outcome of RCT in this study.

Clinical relevance The prognosis of RCT varies by type of tooth; special attention should be given to RCT of molar teeth.
\end{abstract}

Keywords Endodontic $\cdot$ Periapical index $(\mathrm{PAI}) \cdot$ Outcome $\cdot$ Root canal treatment $\cdot$ Tooth type

\section{Introduction}

Previous reports on outcome of root canal treatment (RCT) have introduced apical periodontitis (AP) as a prominent factor weakening the prognosis of RCT [1-5]. The prognosis may also depend on the type of tooth, although earlier evidence is contradictory [6-10], and the results by type of tooth are rarely stratified by periapical status.

Type of tooth is important in clinical work when assessing treatment options and informing patients.

Erika Laukkanen

erika.laukkanen@fimnet.fi

1 Department of Oral and Maxillofacial Diseases, University of Helsinki, P.O. Box 41, FI-00014 Helsinki, Finland

2 Department of Social Services and Health Care, Oral Health Care, P.O. Box 6000, FI-00099 City of Helsinki, Finland

3 Department of Oral and Maxillofacial Diseases, HUS, P.O. Box 263, FI-00029 Helsinki, Finland
However, it has seldom been included in multifactorial models examining factors possibly affecting the prognosis of RCT. Periapical healing seems to follow RCT more frequently in premolars and anterior teeth than in molars [6-8] and in single-rooted than in multirooted teeth [11, 12]. A systematic review of primary RCTs concluded, however, that there was no difference in outcome by type of tooth, but discussed that the evidence is weakened by the fact that the studies had not stratified their results by periapical status [13].

Previous studies have shown consistently that AP preceding RCT affects the outcome negatively; success rates (SRs) vary between 92 and $96 \%$ for teeth without AP and between 74 and $86 \%$ for teeth with AP in primary (first-time) RCTs [2, 12, 14]. Secondary (retreatment) RCTs are mostly indicated by the presence of AP, resulting in SRs between 62 and $83 \%$ [7, 12, 14].

This retrospective study investigated the impact of type of tooth on the outcome of RCT taking into account the presence of preoperative AP and treatment modality (primary or secondary RCT). 


\section{Material and methods}

\section{Ethical consideration}

This study was approved by the Department of Social Services and Health Care of the City of Helsinki (HEL 2012-012378). Data were collected from electronic patient records and radiographs and stored in a database using running numbers as patient identification.

\section{Setting and cases}

All RCTs, with no restriction by type of tooth, were performed by fourth- and fifth-year dental students under tight individual supervision of qualified endodontists. Dental students at the University of Helsinki performed their clinical training at Helsinki University Clinic as part of the public oral health service of the City of Helsinki. Since 2001, these services have been open to all citizens. The patients receiving RCT were either admitted for comprehensive dental care by making an appointment themselves or upon referral for RCT by dentists working in other units of the public services. RCT followed a strict protocol emphasizing aseptic control.

Patients who underwent RCT at Helsinki University Clinic between 2008 and 2011 formed the target population. The inclusion criteria were as follows: a follow-up radiograph taken a minimum of 6 months after root canal filling, diagnosable pre- and postoperative radiographs available, adequate patient records of the RCT available, no fractured instrument existing in the canals preoperatively, and no endodontic surgery preplanned for the case.

\section{Data recordings}

Data collected from patient documents included the type of tooth as anterior (incisors and canines), premolars, and molars, separately for maxillary and mandibular teeth. We recorded preoperative periapical status as apical periodontitis (AP) or no apical periodontitis (NAP) and treatment modality as primary (first-time) or secondary (retreatment) RCT. Patients' details included gender and age in years.

\section{Clinical protocol}

The general protocol for endodontic treatment at Helsinki University Clinic at the time of the investigation is detailed below.

Before RCT, a preoperative radiograph is taken and the tooth is assessed in terms of restorability, periodontal status, and relevance in occlusion. The tooth is anesthetized (when needed), and caries and defective restorations are removed. An access cavity is made, root canals localized, rubber dam placed, and working field disinfected with $0.5 \%$ chlorhexidine
$+96 \%$ ethanol solution $\left(\right.$ Klorhexol $^{\circledR}$; Takeda OY, Helsinki, Finland). Working length is determined using an electronic apex locator and confirmed with a radiograph when needed. Chemo-mechanical debridement is carried out with nickeltitanium (NiTi) hand files (K-files) and with rotary NiTi instruments (Profile ${ }^{\circledR}$; Dentsply Sirona, Inc., York, PA, USA) with a minimum apical preparation size \#35, taper 4\%. For retreatment cases, the gutta-percha is removed using rotary instruments (R-endo ${ }^{\circledR}$; Micro-Mega ${ }^{\circledR}$ SA, Besancon Cedex, France, or Protaper ${ }^{\circledR}$ Universal D1-3; Dentsply Tulsa Dental Specialties, Johnson City, TN, USA) and chloroform, if needed. Copious amounts of $0.5-1.0 \%$ sodium hypochlorite are used for irrigation. At the end of the preparation, the smear layer is removed with $17 \%$ ethylenediaminetetraacetic acid (EDTA). Klorhexol ${ }^{\circledR}$ is used for final irrigation. Most RCTs (94\%), including treatments of vital teeth, are carried out on multiple visits for scheduling reasons. Between visits, the root canals are dressed with calcium hydroxide. A master cone radiograph is taken before the root canal filling. The root canals are obturated using the cold lateral condensation technique with gutta-percha and sealer (AH Plus ${ }^{\circledR ;}$ Dentsply Sirona, Inc., York, PA, USA), and a postoperative radiograph is taken. The tooth is either restored in the same visit or temporized with two layers of temporary filling material $\left(\mathrm{Cavit}^{\mathrm{TM}}\right.$ G; $3 \mathrm{M}^{\mathrm{TM}}$, St. Paul, MN, USA; and IRM ${ }^{\circledR}$; Dentsply Caulk, Milford, DE, USA; or Cavit ${ }^{\mathrm{TM}}-\mathrm{G}$ and resin-modified glass ionomer) until final restoration.

\section{Assessment of radiographs}

A majority of images were intraoral periapical radiographs. In some cases, if a panoramic radiograph was available and diagnosable, it was used in addition or solely (9\% of cases) for assessment. Periapical radiographs were taken using a beamguiding device and the paralleling technique. All radiographs were digital. The radiographs were assessed separately from clinical information, in a room with dimmed lights and a highquality computer screen (EIZO ${ }^{\circledR}$ RadiForce MX220W; EIZO Corporation, Ishikawa, Japan). The periapical status was defined using the periapical index (PAI), a five-step scoring system with each step representing a shift from healthy periapical tissues to severe AP [15]. Preceding the assessment of PAI, the two examiners (a qualified endodontist, A.K., and an endodontics postgraduate student, E.L.) observed a set of 50 various radiographs. Written instructions and reference radiographs were available while examining the radiographs. For multirooted teeth, a PAI score was assigned to each root but recorded by tooth as the greatest score of the roots. If in doubt between scores, the greater PAI score was chosen. The two examiners evaluated the radiographs by discussing them to reach consensus. In addition, an oral and maxillofacial radiologist was consulted about radiographs of maxillary molars because of their complex anatomy and position. 
Outcome was recorded as follows:

1. Healthy: healthy periapical tissues (PAI scores 1-2)

2. Healing: apical radiolucency considerably smaller in follow-up radiograph than in preoperative radiograph, but not completely disappeared (PAI scores 3-4) in 4 years

3. No healing:

a) Periapical radiolucency remained the same (PAI scores 3-5)

b) Teeth extracted for endodontic reasons (persisting apical infection, fistula) or for reasons not recorded in documents available after root filling

c) Teeth receiving periapical surgery

4. Deteriorated: periapical radiolucency enlarged or a new periapical radiolucency emerged (PAI scores 3-5)

The outcome was then dichotomized as successful (healthy and healing) or unsuccessful (no healing and deteriorated).

\section{Statistical analysis}

To evaluate differences between the groups, we used chisquared tests and Fisher's exact test for frequencies and $t$ tests for mean values. We considered $p$ values below 0.05 to be statistically significant. Further, we analyzed factors related to outcome. We applied logistic regression modeling and calculated odds ratios (ORs) and their 95\% confidence intervals (95\% CIs). The Hosmer and Lemeshow test was used to assess goodness of fit for the models.

\section{Results}

\section{Characteristics of cases}

The mean age of all patients was 51.5 years (standard deviation [SD] 15.0; range 10-83). For patients receiving primary RCT, the mean age was 50.0 years (SD 15.7; range 10-83), and for patients receiving secondary RCT, 54.6 years (SD 13.0; range 21-83). This age difference was statistically significant $(p<0.001)$. Of patients, $51 \%$ were male and $49 \%$ female.

A total of 640 permanent teeth with RCT were subject to analysis. Of these teeth, $44 \%$ were molars, $32 \%$ premolars, and $24 \%$ anterior teeth. The characteristics of root canaltreated teeth and patients are presented in Table 1.

AP occurred preoperatively in $60.5 \%$ of teeth and varied by type of tooth; mandibular anterior teeth had AP more often than other types of teeth $(77.1 \%$ vs. $59.1 \% ; p=0.014)$. Male patients had AP more often than female patients $(64.5 \%$ vs. $56.2 \% ; p=0.032)$.

\section{Outcome}

The overall success rate (SR) for all RCTs was $84.1 \%$. The time range of outcome assessment was 6-71 months. Only the most recent follow-up of each tooth was included in the data. The SRs for different lengths of follow-up are presented in Table 2.

Premolars had a significantly greater SR than molars $(88.8 \%$ vs. $79.7 \% ; p=0.007)$, but no such difference existed when premolars were compared with anterior teeth $(88.8 \%$ vs. $85.6 \% ; p=0.363$ ) or anterior teeth were compared with molars $(85.6 \%$ vs. $79.7 \% ; p=0.128)$. No statistically significant difference was present in SRs of maxillary and mandibular teeth.

Teeth with primary RCT had a significantly greater SR than teeth with secondary RCT $(88.3 \%$ vs. $75.5 \% ; p<0.001)$. The difference between primary and secondary treatments existed also according to the type of tooth (anterior, premolars, molars). The greatest SRs were with primary RCTs of maxillary and mandibular premolars, $93.7 \%$ and $93.9 \%$, respectively. The smallest SRs were for secondary RCTs of mandibular anterior teeth and maxillary and mandibular molars, $66.7 \%$, $70.0 \%$, and $70.6 \%$, respectively (Table 3 ).

The SR for teeth with AP preoperatively, including both primary and secondary RCTs, was significantly smaller than for teeth without AP $(77.3 \%$ vs. $94.5 \% ; p<0.001)$. The difference varied by type of tooth; maxillary premolars $(p=$ $0.001)$, mandibular premolars $(p=0.025)$, and mandibular molars $(p<0.001)$ showed the greatest differences (Table 4). The SR was smallest for mandibular molars with AP preoperatively and greatest for maxillary premolars without AP, $71.3 \%$ and $100 \%$, respectively.

Table 5 presents logistic regression modeling for evaluating the outcome of RCT. Success was more likely for anterior teeth and premolars than for molars (OR 1.7; 95\% CI 1.1-2.7), in the absence than in the presence of AP (OR 4.3; 95\% CI 2.4-7.8), in primary than in secondary RCT (OR 2.3; 95\% CI 1.4-3.6), and in female patients than in male patients (OR 1.9; 95\% CI 1.2-3.1). The age of the patient or the location of the tooth (maxilla vs. mandible) had no impact on the success of RCT.

\section{Discussion}

This study investigated the impact of type of tooth on the outcome of RCT. We found an overall SR of $84.1 \%$, which is comparable to rates reported in recent international studies $[3,5,7,12,16]$. The success was poorer in molars, in teeth with preoperative AP, in secondary RCTs, and in male patients. The impact of preoperative AP on the outcome of RCT varied by type of tooth.

The diversity of our sample speaks for the generalizability of our findings. The patients of this study came from the 
Table 1 Characteristics of root canal-treated teeth $(n=640)$ enrolled in the study

\begin{tabular}{|c|c|c|c|c|c|c|c|}
\hline \multirow[t]{2}{*}{ Characteristic } & \multicolumn{2}{|c|}{ All treated teeth } & \multicolumn{2}{|c|}{ Primary RCT } & \multicolumn{2}{|c|}{ Secondary RCT } & \multirow[t]{2}{*}{$p$ value } \\
\hline & $n$ & $\%$ & $n$ & $\%$ & $n$ & $\%$ & \\
\hline \multicolumn{8}{|c|}{ Location and type of tooth } \\
\hline Maxilla (all teeth) & 335 & 52 & 224 & 35 & 111 & 17 & 0.226 \\
\hline Anterior & 105 & 16 & 77 & 12 & 28 & 4 & \\
\hline Premolars & 122 & 19 & 79 & 12 & 43 & 7 & \\
\hline Molars & 108 & 17 & 68 & 11 & 40 & 6 & \\
\hline Mandible (all teeth) & 305 & 48 & 204 & 32 & 101 & 16 & 0.144 \\
\hline Anterior & 48 & 7 & 33 & 5 & 15 & 2 & \\
\hline Premolars & 84 & 14 & 49 & 8 & 35 & 6 & \\
\hline Molars & 173 & 27 & 122 & 19 & 51 & 8 & \\
\hline Patients' gender & & & & & & & 0.219 \\
\hline Male & 327 & 51 & 226 & 35 & 101 & 16 & \\
\hline Female & 313 & 49 & 202 & 32 & 111 & 17 & \\
\hline Patients' age (years) & & & & & & & 0.010 \\
\hline$<35$ & 92 & 15 & 75 & 12 & 17 & 3 & \\
\hline $35-44$ & 92 & 14 & 65 & 10 & 27 & 4 & \\
\hline $45-54$ & 172 & 27 & 113 & 18 & 59 & 9 & \\
\hline $55-64$ & 151 & 24 & 95 & 15 & 56 & 9 & \\
\hline$\geq 65$ & 133 & 20 & 80 & 12 & 53 & 8 & \\
\hline Total & 640 & 100 & 428 & 67 & 212 & 33 & \\
\hline
\end{tabular}

$p$ values based on chi-squared test refer to differences between primary and secondary root canal treatments (RCTs). Cell percentages refer to proportions of all RCT teeth $(n=640)$ general population, which bodes well for the absence of a selection bias. The wide age range of the patients (1083 years) ensures representative data. Compared with previous studies, where $17-31 \%$ of RCT teeth were molars $[6,7$, 17], in our material, molars were slightly over-represented (44\%). The distribution of RCT teeth in our data is, however, similar to that in a large Finnish survey material consisting of 6101 panoramic radiographs [18]. The overall SR reported in different studies may depend on proportions of various types of teeth in the study sample [19] and the proportion of teeth with AP preoperatively [20]. Our study sample contained $60.5 \%$ teeth with AP, which is more than in many earlier studies (35-57\%) [7, 8, 11, 12, 21]. A limitation of this study is that the material is collected from patient documents only.
However, a similar approach has been used in many previous reports $[9,10,22-24]$.

The RCTs of this study were carried out by fourth- and fifth-year dental students, which could be considered a limitation of this study. However, under the strict supervision by endodontists, the RCTs performed by students succeed well. Similar clinical settings are common in many previous outcome studies, too $[1,8,9,14,17]$.

We defined the success of RCT by periapical radiography, which is still considered the standard examination [25] and is in everyday use despite the increasing utilization of conebeam computed tomography. For a minority (9\%) of cases, we used panoramic radiography. Panoramic radiographs are usually considered less sensitive in periapical diagnosis, but
Table 2 Success (\%) of root canal treatments according to the length of follow-up

\begin{tabular}{|c|c|c|c|c|c|c|c|c|}
\hline \multirow[t]{2}{*}{ Follow-up (months) } & \multirow[b]{2}{*}{$n$} & \multirow[b]{2}{*}{$\%$} & \multicolumn{2}{|c|}{ Success, healthy/healed } & \multicolumn{2}{|c|}{ Success, healing } & \multicolumn{2}{|c|}{ Success, total } \\
\hline & & & $n$ & $\%$ & $n$ & $\%$ & $n$ & $\%$ \\
\hline $6-11$ & 121 & 19 & 72 & 59.5 & 24 & 19.8 & 96 & 79.3 \\
\hline $12-24$ & 298 & 47 & 209 & 70.1 & 41 & 13.8 & 250 & 83.9 \\
\hline$>24$ & 221 & 34 & 170 & 76.9 & 22 & 10.0 & 192 & 86.9 \\
\hline Total & 640 & 100 & 451 & 70.5 & 87 & 13.6 & 538 & 84.1 \\
\hline
\end{tabular}

Success, healthy (teeth with no initial apical periodontitis)/healed (teeth with initial apical periodontitis) = radiographic findings scored as "healthy" at follow-up. Success, healing = radiographic findings scored as "healing" at follow-up 
Table 3 Success (\%) of root canal treatment (RCT) according to treatment modality and type of tooth; $p$ values refer to differences between primary and secondary RCT

\begin{tabular}{|c|c|c|c|c|c|c|c|}
\hline \multirow[t]{2}{*}{ Type of tooth by jaw } & \multicolumn{2}{|c|}{ Primary RCT } & \multicolumn{2}{|c|}{ Secondary RCT } & \multicolumn{2}{|c|}{ Total } & \multirow[t]{2}{*}{$p^{\mathrm{a}}$ value } \\
\hline & $n$ & Success $^{\mathrm{b}}(\%)$ & $n$ & Success $^{\mathrm{b}}(\%)$ & $n$ & Success $^{\mathrm{b}}(\%)$ & \\
\hline \multicolumn{8}{|l|}{ Anterior } \\
\hline Maxilla & 77 & 89.6 & 28 & 82.1 & 105 & 87.6 & 0.304 \\
\hline Mandible & 33 & 87.9 & 15 & 66.7 & 48 & 81.3 & 0.081 \\
\hline Total & 110 & 89.1 & 43 & 76.7 & 153 & 85.6 & 0.050 \\
\hline \multicolumn{8}{|l|}{ Premolars } \\
\hline Maxilla & 79 & 93.7 & 43 & 81.4 & 122 & 89.3 & 0.061 \\
\hline Mandible & 49 & 93.9 & 35 & 80.0 & 84 & 88.1 & 0.053 \\
\hline Total & 128 & 93.8 & 78 & 80.8 & 206 & 88.8 & 0.004 \\
\hline \multicolumn{8}{|l|}{ Molars } \\
\hline Maxilla & 68 & 85.3 & 40 & 70.0 & 108 & 79.6 & 0.057 \\
\hline Mandible & 122 & 83.6 & 51 & 70.6 & 173 & 79.8 & 0.052 \\
\hline Total & 190 & 84.2 & 91 & 70.3 & 281 & 79.7 & 0.007 \\
\hline Total & 428 & 88.3 & 212 & 75.5 & 640 & 84.1 & $<0.001$ \\
\hline
\end{tabular}

${ }^{a}$ Statistical evaluation by means of chi-squared tests or Fisher's exact test

${ }^{\mathrm{b}}$ Success = radiographic findings scored as "healthy" or "healing" at a minimum 6-month follow-up contemporary panoramic radiographs with improved quality can be as accurate or even more accurate than periapical radiographs in molar regions [26]. We took teeth instead of roots as units of evaluation to avoid the possible skewness related to root-based analyses. All of the radiographs were assessed by two authors, who discussed the findings to reach consensus. Consequently, the inter-observer agreement was not measured, which is a limitation of this study.
We considered both "healthy" and "healing" teeth as successful as the follow-up period varied. In other words, we used "loose criteria," as suggested by a systematic review [27]. Six months was the minimum follow-up. Almost $90 \%$ of periapical lesions that are going to heal eventually show signs of healing by 12 months, and reversal of the healing process is considered to be rare [28]. The healing can, however, be visible in radiographs rather soon after the RCT [21, 29]. For
Table 4 Success (\%) of root canal treatment according to preoperative periapical status and type of tooth

\begin{tabular}{|c|c|c|c|c|c|c|}
\hline \multirow[t]{2}{*}{ Type of tooth by jaw } & \multicolumn{2}{|c|}{ NAP } & \multicolumn{2}{|l|}{ AP } & \multirow[t]{2}{*}{$p^{\mathrm{a}}$ value } & \multirow[b]{2}{*}{$\mathrm{RD}$} \\
\hline & $n$ & Success $^{\mathrm{b}}(\%)$ & $n$ & Success $^{\mathrm{b}}(\%)$ & & \\
\hline \multicolumn{7}{|l|}{ Anterior } \\
\hline Maxilla & 45 & 93.3 & 60 & 83.3 & 0.124 & 10.0 \\
\hline Mandible & 11 & 90.9 & 37 & 78.4 & 0.662 & 12.5 \\
\hline Total & 56 & 92.9 & 97 & 81.4 & 0.053 & 11.5 \\
\hline \multicolumn{7}{|l|}{ Premolars } \\
\hline Maxilla & 53 & 100.0 & 69 & 81.2 & 0.001 & 18.8 \\
\hline Mandible & 36 & 97.2 & 48 & 81.3 & 0.025 & 15.9 \\
\hline Total & 89 & 98.9 & 117 & 81.2 & $<0.001$ & 17.7 \\
\hline \multicolumn{7}{|l|}{ Molars } \\
\hline Maxilla & 43 & 88.4 & 65 & 73.8 & 0.057 & 14.6 \\
\hline Mandible & 65 & 93.8 & 108 & 71.3 & $<0.001$ & 22.5 \\
\hline Total & 108 & 91.7 & 173 & 72.3 & $<0.001$ & 19.4 \\
\hline Total & 253 & 94.5 & 387 & 77.3 & $<0.001$ & 17.2 \\
\hline
\end{tabular}

$p$ values refer to differences between NAP and AP teeth

$N A P$ no apical periodontitis, $A P$ apical periodontitis, $R D$ rate difference in percentage points

${ }^{a}$ Statistical evaluation by means of chi-squared tests or Fisher's exact test

${ }^{\mathrm{b}}$ Success = radiographic findings scored as "healthy" or "healing" at a minimum 6-month follow-up 
Table 5 Success of root canal treatment (RCT) evaluated by means of logistic regression modeling

\begin{tabular}{llllll}
\hline & Estimate & SE & OR & $95 \%$ CI & $p$ value \\
\hline Type of tooth & 0.541 & 0.239 & 1.7 & $1.1-2.7$ & 0.023 \\
Maxilla vs. mandible & 0.143 & 0.234 & 1.2 & $0.7-1.8$ & 0.542 \\
NAP vs. AP & 1.459 & 0.306 & 4.3 & $2.4-7.8$ & 0.000 \\
$1^{\circ}$ vs. $2^{\circ}$ RCT & 0.828 & 0.234 & 2.3 & $1.4-3.6$ & 0.000 \\
Age & 0.004 & 0.008 & 1.0 & $1.0-1.0$ & 0.644 \\
Female vs. male & 0.662 & 0.237 & 1.9 & $1.2-3.1$ & 0.005 \\
HL $=0.519$ & & & & & \\
\hline
\end{tabular}

Success $=$ radiographic findings scored as "healthy" or "healing" at a minimum 6-month follow-up. Type of tooth $=$ anterior and premolars vs. molars

$1^{\circ} R C T$ primary root canal treatment, $2^{\circ} R C T$ secondary root canal treatment, $A P$ apical periodontitis, $N A P$ no apical periodontitis, $S E$ standard error, $O R$ odds ratio, $C I$ confidence interval, $H L$ Hosmer and Lemeshow's test for goodness of fit

reasons related to the patient's or student's schedules, some follow-ups took place later than planned, which can be considered a limitation of our study. Similar variation in outcome assessment periods exists, however, in many previous studies $[1,5,16,17]$. In case the lesion was not fully healed in 4 years, we considered the treatment failed according to the ESE guidelines [30], even though on rare occasions, healing can take considerably longer [23].

The overall SR (84.1\%) found here is in line with many earlier studies $[3,5,7,12,16]$ and with a meta-analysis [31] reporting a cumulative SR around $83 \%$. We found RCT in molars less likely to succeed than in anterior teeth and premolars. The impact of type of tooth on outcome has been evaluated before with varying results $[6-10,13]$, but rarely in a multifactorial model including other factors consistently shown to worsen the prognosis.

We found the SR for teeth with AP to be less than the rate for teeth without AP, supporting the conclusions from systematic reviews [13,32]. The impact of AP on outcome varied by type of tooth. In the presence of AP, maxillary and mandibular molars had the smallest SRs, but the rate differences (RD) between teeth with and without AP were greatest for maxillary premolars and mandibular molars. In a French study with 91 patients, the risk of failure was seven times greater for posterior than for anterior teeth without AP [33]. In teeth with AP, the same study reported a fourfold higher risk of failure for multirooted teeth than for single-rooted teeth. A study investigating 100 teeth with AP found an overall SR of 95\% [17], but only $17 \%$ of teeth in their study were molars and the results were not presented by type of tooth. Therefore, the results cannot be compared with ours. A recent Swedish study examined only maxillary molars $(n=73), 86 \%$ of which had AP preoperatively, and reported an SR of $81 \%$ [34], which is close to our result for maxillary molars $(79.6 \%)$.
We found primary RCTs to be more likely to succeed than secondary RCTs, consistent with many previous studies [7, $12,16,17]$. A prospective study, however, revealed no such difference [5]. In our study, there was a significant difference in SRs between primary and secondary RCTs also for the type of tooth (anterior, premolars, and molars). A study using multifactorial analysis separately for primary and secondary treatments found molars to be less likely to succeed than anterior teeth and premolars, but only for secondary treatments [4]. Another study investigating secondary treatments reported no difference in outcome by type of tooth [35]. In our study, the SR of secondary RCTs of mandibular anterior teeth was relatively small, but their amount was insufficient to show a statistical difference, and therefore, further investigation is needed to establish the prognosis of RCTs in mandibular anterior teeth.

The age of the patient had no impact on the success of RCT, which is in line with many earlier studies [11, 12, 35, 36], although some contradictory findings also exist $[8,16]$. We found RCT to be twice as likely to succeed in women than in men, consistent with a study published in 1983 analyzing 20year endodontic success [24] and another study published in 2001 [37]. This gender difference is difficult to interpret and is contrary to some previous studies [2, 3, 9, 10, 14, 22]. A recent epidemiological study in Finland found men to have AP more often than women, despite root-filled teeth being less frequent in men [38]. In our sample, AP occurred preoperatively more often in men.

All RCTs evaluated in this study were carried out under a strict protocol, which adds to the value of our findings. The results indicate that the success of RCT is to be expected, even in unexperienced hands, when guidelines are followed and good aseptic control is maintained. Epidemiological studies reflect the outcome of RCTs in general dental practice, and they show AP in 16-44\% of root canal-treated teeth [38-40]. Many general dentists find RCTs difficult and stressful to perform [41], and cite economic and time constraints as reasons for accepting substandard quality in root fillings [42]. Attention should be given to the circumstances in which RCTs are performed and especially to the apparently infrequent use of a rubber dam [43].

\section{Conclusion}

The overall outcome of RCT was comparable to that found in recent international studies. Apart from existing AP and retreatment, which consistently have been shown to worsen the prognosis, also, the type of tooth and gender of the patient had a significant influence on the outcome of RCT. The prognosis is not the same for every RCT; special attention should be given to RCTs of molars. 
Acknowledgements Open access funding provided by University of Helsinki including Helsinki University Central Hospital. The authors thank Walter Koskinen for the help in assessing the radiographs, Vesa Ylönen for assistance in data analysis, and Eero Kerosuo for valuable comments during the preparation of the manuscript.

Funding This work was supported by personal grants to E.L. by the Finnish Dental Society Apollonia and the Finnish Association for Dentists in Public Health Care.

\section{Compliance with ethical standards}

Conflict of interest The authors declare that they have no conflict of interest.

Ethical approval This article does not contain any studies with human participants or animals performed by any of the authors.

Informed consent For this type of study, formal consent is not required.

Open Access This article is distributed under the terms of the Creative Commons Attribution 4.0 International License (http:// creativecommons.org/licenses/by/4.0/), which permits unrestricted use, distribution, and reproduction in any medium, provided you give appropriate credit to the original author(s) and the source, provide a link to the Creative Commons license, and indicate if changes were made.

Publisher's note Springer Nature remains neutral with regard to jurisdictional claims in published maps and institutional affiliations.

\section{References}

1. Ørstavik D, Qvist V, Stoltze K (2004) A multivariate analysis of the outcome of endodontic treatment. Eur J Oral Sci 112(3):224-230. https://doi.org/10.1111/j.1600-0722.2004.00122.x

2. Friedman S, Abitbol S, Lawrence HP (2003) Treatment outcome in endodontics: the Toronto Study. Phase 1: initial treatment. J Endod 29(12):787-793. https://doi.org/10.1097/00004770-200312000-00001

3. de Chevigny C, Dao TT, Basrani BR, Marquis V, Farzaneh M, Abitbol S, Friedman S (2008) Treatment outcome in endodontics: the Toronto study-phases 3 and 4: orthograde retreatment. J Endod 34(2):131-137. https://doi.org/10.1016/j.joen.2007.11.003

4. Imura N, Pinheiro ET, Gomes BP, Zaia AA, Ferraz CC, SouzaFilho FJ (2007) The outcome of endodontic treatment: a retrospective study of 2000 cases performed by a specialist. J Endod 33(11): 1278-1282. https://doi.org/10.1016/j.joen.2007.07.018

5. Ng YL, Mann V, Gulabivala K (2011) A prospective study of the factors affecting outcomes of nonsurgical root canal treatment: part 1: periapical health. Int Endod J 44(7):583-609. https://doi.org/10. $1111 / \mathrm{j} .1365-2591.2011 .01872 . x$

6. Cheung GS, Chan TK (2003) Long-term survival of primary root canal treatment carried out in a dental teaching hospital. Int Endod $\mathbf{J}$ 36(2):117-128

7. Ricucci D, Russo J, Rutberg M, Burleson JA, Spangberg LS (2011) A prospective cohort study of endodontic treatments of 1,369 root canals: results after 5 years. Oral Surg Oral Med Oral Pathol Oral Radiol Endod 112(6):825-842. https://doi.org/10.1016/j.tripleo. 2011.08.003

8. Lee AH, Cheung GS, Wong MC (2012) Long-term outcome of primary non-surgical root canal treatment. Clin Oral Investig 16(6):1607-1617. https://doi.org/10.1007/s00784-011-0664-2
9. Benenati FW, Khajotia SS (2002) A radiographic recall evaluation of 894 endodontic cases treated in a dental school setting. J Endod 28(5):391-395. https://doi.org/10.1097/00004770-20020500000011

10. Hoskinson SE, Ng YL, Hoskinson AE, Moles DR, Gulabivala K (2002) A retrospective comparison of outcome of root canal treatment using two different protocols. Oral Surg Oral Med Oral Pathol Oral Radiol Endod 93(6):705-715

11. Farzaneh M, Abitbol S, Lawrence H, Friedman S (2004) Treatment outcome in endodontics - the Toronto Study. Phase II: initial treatment. J Endod 30(5):302-309. https://doi.org/10.1097/00004770200405000-00002

12. de Chevigny C, Dao TT, Basrani BR, Marquis V, Farzaneh M, Abitbol S, Friedman S (2008) Treatment outcome in endodontics: the Toronto study-phase 4: initial treatment. J Endod 34(3):258 263. https://doi.org/10.1016/j.joen.2007.10.017

13. Ng YL, Mann V, Rahbaran S, Lewsey J, Gulabivala K (2008) Outcome of primary root canal treatment: systematic review of the literature - part 2. Influence of clinical factors. Int Endod J 41(1):6-31. https://doi.org/10.1111/j.1365-2591.2007.01323.x

14. Sjögren U, Hägglund B, Sundqvist G, Wing K (1990) Factors affecting the long-term results of endodontic treatment. J Endod 16(10):498-504. https://doi.org/10.1016/S0099-2399(07)80180-4

15. Ørstavik D, Kerekes K, Eriksen HM (1986) The periapical index: a scoring system for radiographic assessment of apical periodontitis. Endod Dent Traumatol 2(1):20-34

16. Azim AA, Griggs JA, Huang GT (2016) The Tennessee study: factors affecting treatment outcome and healing time following nonsurgical root canal treatment. Int Endod J 49(1):6-16. https:// doi.org/10.1111/iej.12429

17. Siqueira JF Jr, Rocas IN, Riche FN, Provenzano JC (2008) Clinical outcome of the endodontic treatment of teeth with apical periodontitis using an antimicrobial protocol. Oral Surg Oral Med Oral Pathol Oral Radiol Endod 106(5):757-762. https://doi.org/10. 1016/j.tripleo.2008.06.007

18. Huumonen S, Vehkalahti MM, Nordblad A (2012) Radiographic assessments on prevalence and technical quality of endodonticallytreated teeth in the Finnish population, aged 30 years and older. Acta Odontol Scand 70(3):234-240. https://doi.org/10.3109/ 00016357.2011.637510

19. Friedman S (2002) Prognosis of initial endodontic therapy. Endod Top 2002(2):59-88

20. Ørstavik D, Pitt Ford T (2008) Essential endodontology: prevention and treatment of apical periodontitis, 2nd edn. Blackwell Munksgaard Ltd, Oxford, UK

21. Huumonen S, Ørstavik D (2013) Radiographic follow-up of periapical status after endodontic treatment of teeth with and without apical periodontitis. Clin Oral Investig 17(9):2099-2104. https://doi.org/10.1007/s00784-013-0926-2

22. Smith CS, Setchell DJ, Harty FJ (1993) Factors influencing the success of conventional root canal therapy-a five-year retrospective study. Int Endod J 26(6):321-333

23. Molven O, Halse A, Fristad I, MacDonald-Jankowski D (2002) Periapical changes following root-canal treatment observed 20-27 years postoperatively. Int Endod J 35(9):784-790

24. Swartz DB, Skidmore AE, Griffin JA, Jr. (1983) Twenty years of endodontic success and failure. J Endod 9(5):198-202. https://doi. org/10.1016/S0099-2399(83)80092-2

25. Patel S, Durack C, Abella F, Shemesh H, Roig M, Lemberg K (2015) Cone beam computed tomography in endodontics - a review. Int Endod J 48(1):3-15. https://doi.org/10.1111/iej.12270

26. Ridao-Sacie C, Segura-Egea JJ, Fernandez-Palacin A, BullonFernandez P, Rios-Santos JV (2007) Radiological assessment of periapical status using the periapical index: comparison of periapical radiography and digital panoramic radiography. Int 
Endod J 40(6):433-440. https://doi.org/10.1111/j.1365-2591.2007. 01233.x

27. Ng YL, Mann V, Rahbaran S, Lewsey J, Gulabivala K (2007) Outcome of primary root canal treatment: systematic review of the literature - part 1. Effects of study characteristics on probability of success. Int Endod J 40(12):921-939. https://doi.org/10.1111/j. 1365-2591.2007.01322.x

28. Ørstavik D (1996) Time-course and risk analyses of the development and healing of chronic apical periodontitis in man. Int Endod $\mathrm{J}$ 29(3):150-155

29. Kerosuo E, Orstavik D (1997) Application of computerised image analysis to monitoring endodontic therapy: reproducibility and comparison with visual assessment. Dentomaxillofac Radiol 26(2):79-84. https://doi.org/10.1038/sj.dmfr.4600207

30. European Society of Endodontology (2006) Quality guidelines for endodontic treatment: consensus report of the European Society of Endodontology. Int Endod J 39(12):921-930. https://doi.org/10. $1111 /$ j.1365-2591.2006.01180.x

31. Kojima K, Inamoto K, Nagamatsu K, Hara A, Nakata K, Morita I, Nakagaki H, Nakamura H (2004) Success rate of endodontic treatment of teeth with vital and nonvital pulps. A meta-analysis. Oral Surg Oral Med Oral Pathol Oral Radiol Endod 97(1):95-99. https:// doi.org/10.1016/S1079210403004803

32. Ng YL, Mann V, Gulabivala K (2008) Outcome of secondary root canal treatment: a systematic review of the literature. Int Endod $\mathrm{J}$ 41(12):1026-1046. https://doi.org/10.1111/j.1365-2591.2008. 01484.x

33. Castelot-Enkel B, Nguyen JM, Armengol V, Volteau C, Laboux O, Lombrail P, Weiss P (2013) A recall program for the outcome of conventional root canal treatment performed in a teaching hospital. Acta Odontol Scand 71(6):1399-1409. https://doi.org/10.3109/ 00016357.2013 .765591

34. Almohareb R, Ahlquist M, Sandborgh Englund G (2016) The association between root canal filling and treatment outcome. Swedish Dental J (40):133-142
35. Eyuboglu TF, Olcay K, Ozcan M (2017) A clinical study on singlevisit root canal retreatments on consecutive 173 patients: frequency of periapical complications and clinical success rate. Clin Oral Investig 21(5):1761-1768. https://doi.org/10.1007/s00784-016-1957-2

36. Shakiba B, Hamedy R, Pak JG, Barbizam JV, Ogawa R, White SN (2017) Influence of increased patient age on longitudinal outcomes of root canal treatment: a systematic review. Gerodontology 34(1): 101-109. https://doi.org/10.1111/ger.12231

37. Chugal NM, Clive JM, Spangberg LS (2001) A prognostic model for assessment of the outcome of endodontic treatment: effect of biologic and diagnostic variables. Oral Surg Oral Med Oral Pathol Oral Radiol Endod 91(3):342-352. https://doi.org/10.1067/moe.2001.113106

38. Huumonen S, Suominen AL, Vehkalahti MM (2017) Prevalence of apical periodontitis in root filled teeth: findings from a nationwide survey in Finland. Int Endod J 50(3):229-236. https://doi.org/10. 1111/iej.12625

39. Tavares PB, Bonte E, Boukpessi T, Siqueira JF Jr, Lasfargues JJ (2009) Prevalence of apical periodontitis in root canal-treated teeth from an urban French population: influence of the quality of root canal fillings and coronal restorations. J Endod 35(6):810-813. https://doi.org/10.1016/j.joen.2009.03.048

40. Kirkevang LL, Vaeth M, Wenzel A (2012) Ten-year follow-up observations of periapical and endodontic status in a Danish population. Int Endod J 45(9):829-839. https://doi.org/10.1111/j.13652591.2012.02040.x

41. Dahlström L, Lindwall O, Rystedt H, Reit C (2016) 'Working in the dark': Swedish general dental practitioners on the complexity of root canal treatment. Int Endod J 50(7):636-645. https://doi.org/ 10.1111/iej.12675

42. Dahlström L, Lindwall O, Rystedt H, Reit C (2017) 'It's good enough': Swedish general dental practitioners on reasons for accepting substandard root filling quality. Int Endod J 51(S3): e168-e177. https://doi.org/10.1111/iej.12743

43. Ahmad IA (2009) Rubber dam usage for endodontic treatment: a review. Int Endod J 42(11):963-972. https://doi.org/10.1111/j. 1365-2591.2009.01623.x 